Review

\title{
The Soldiers in Societies: Defense, Regulation, and Evolution
}

\author{
Li Tian and Xuguo Zhou ${ }^{\bowtie}$ \\ Department of Entomology, University of Kentucky, Lexington, KY 40546-0091, USA.
}

$\triangle$ Corresponding author: Dr. Xuguo "Joe" Zhou, Department of Entomology, University of Kentucky, S-225 Agricultural Science Center North, Lexington, KY 40546-0091. Phone: 859-257-3125 Fax: 859-323-1120 Email: xuguozhou@uky.edu.

(c) Ivyspring International Publisher. This is an open-access article distributed under the terms of the Creative Commons License (http://creativecommons.org/ licenses/by-nc-nd/3.0/). Reproduction is permitted for personal, noncommercial use, provided that the article is in whole, unmodified, and properly cited.

Received: 2013.06.06; Accepted: 2014.01.02; Published: 2014.03.05

\begin{abstract}
The presence of reproductively altruistic castes is one of the primary traits of the eusocial societies. Adaptation and regulation of the sterile caste, to a certain extent, drives the evolution of eusociality. Depending on adaptive functions of the first evolved sterile caste, eusocial societies can be categorized into the worker-first and soldier-first lineages, respectively. The former is marked by a worker caste as the first evolved altruistic caste, whose primary function is housekeeping, and the latter is highlighted by a sterile soldier caste as the first evolved altruistic caste, whose task is predominantly colony defense. The apparent functional differences between these two fundamentally important castes suggest worker-first and soldier-first eusociality are potentially driven by a suite of distinctively different factors. Current studies of eusocial evolution have been focused largely on the worker-first Hymenoptera, whereas understanding of soldier-first lineages including termites, eusocial aphids, gall-dwelling thrips, and snapping shrimp, is greatly lacking. In this review, we summarize the current state of knowledge on biology, morphology, adaptive functions, and caste regulation of the soldier caste. In addition, we discuss the biological, ecological and genetic factors that might contribute to the evolution of distinct caste systems within eusocial lineages.
\end{abstract}

Key words: Soldier, eusociality, eusocial evolution, termites, Hymenoptera, soldier-first lineage, worker-first lineage.

\section{Introduction}

The origin of eusociality is one of the major transitions in evolutionary history [1]. Eusocial lineages are characterized by cooperative brood care, overlapping generations and reproductive division of labor [2]. The latter is regarded as the hallmark of eusociality $[1,3]$. Eusocality has been documented in phylogenetically distant taxa including insects (Hymenoptera [4], termites [4], aphids [5], thrips [6], and beetles [7]), crustacean (snapping shrimp [8]), and mammals (naked mole rats [9]). Despite the diverse taxonomic distribution, a single characteristic is common to all eusocial lineages: the evolution of a reproductively altruistic caste [4]. It is believed that behavioral and morphological adaptations of these "reproductively selfless" individuals contribute to the major advantages of social living and are essential for the spectacular evolutionary success of eusociality $[2$, $4]$.

Independent origins of eusociality result in remarkable variation in adaptive functions of altruistic castes. Two functionally distinct sterile castes, soldier and worker, are the cornerstones of the eusocial societies $[4,10]$. Workers and soldiers display many distinct characteristics (Fig.1). The worker caste is, typically, the numerically dominant caste in a colony [4], except for the workerless inquiline ant species [11]. Pogonomyrmex colei, an endemic species equipped with a psammophore, a bearded structure for digging and moving sand particles, is often found living commensally with a much larger congeneric species, 
Pogonomyrmex rugosu. With few exceptions (in ants), worker caste exhibits limited morphological modifications (except for the body size) from the reproductives (Fig. 1g-h) [4]. Workers are capable of performing all housekeeping tasks such as nest construction, foraging, brood care and defense $[7,9,12]$. The physical soldier caste is numerically few in the colony, comprising $2-50 \%$ of the population [13-15]. This caste displays morphological and behavioral specializations for defense (Fig. 1a-f), which distinguish them from the reproductive caste or ordinary colony members $[4,16,17]$.

Eusocial lineages exhibit remarkable differences in the evolution of a sterile caste. Based on the very first sterile caste evolved in a society, we categorize these lineages into worker-first and soldier-first eusociality, respectively. In worker-first lineages, which include eusocial Hymenoptera (ants, bees and wasps) [10, 18], naked mole rats [9] and possibly eusocial ambrosia beetles [7], workers are the first sterile caste evolved. In the soldier-first lineages, ranging from termites [10, 18], eusocial aphids [17], gall-dwelling thrips [6], to snapping shrimps [8], the sterile soldier caste is the only, or first evolved sterile caste. Both types of eusociality are highly successful in terms of their biomass, social complexity and ecological dominance $[4,19]$.

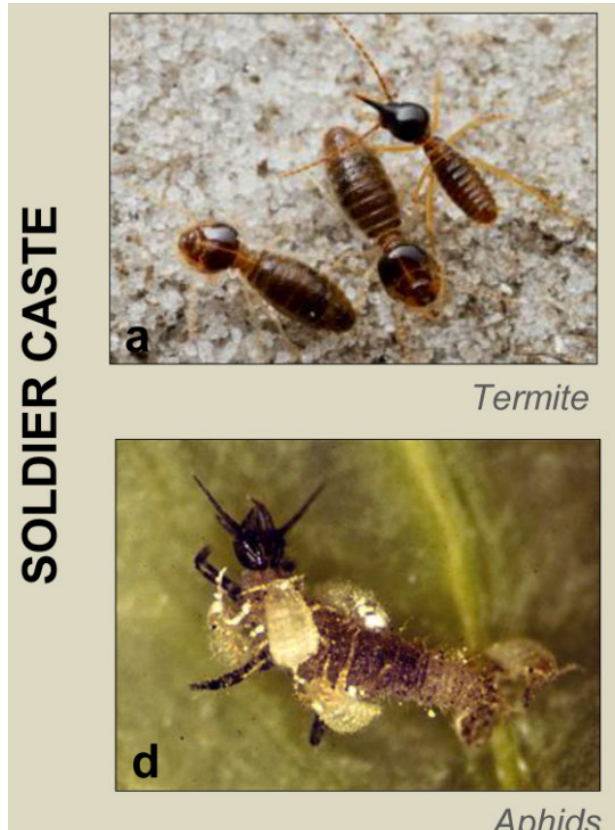

Aphids

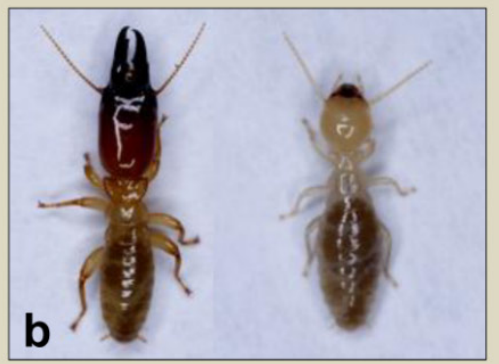

Termite

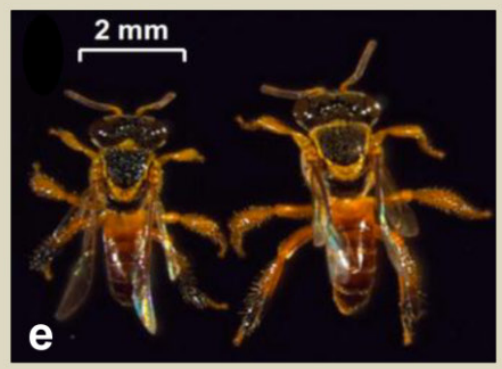

Stingless bee

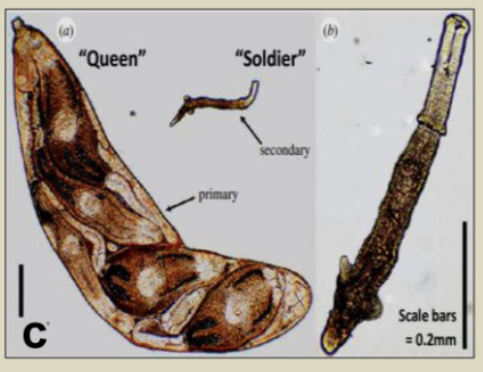

Trematode

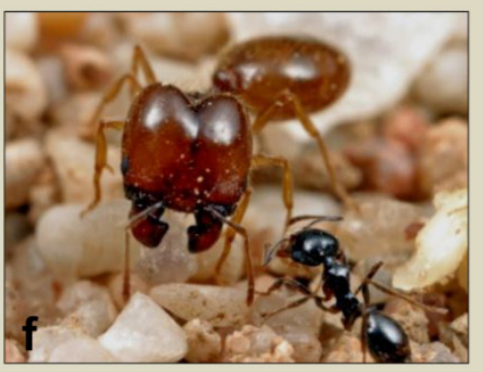

Hymenoptera

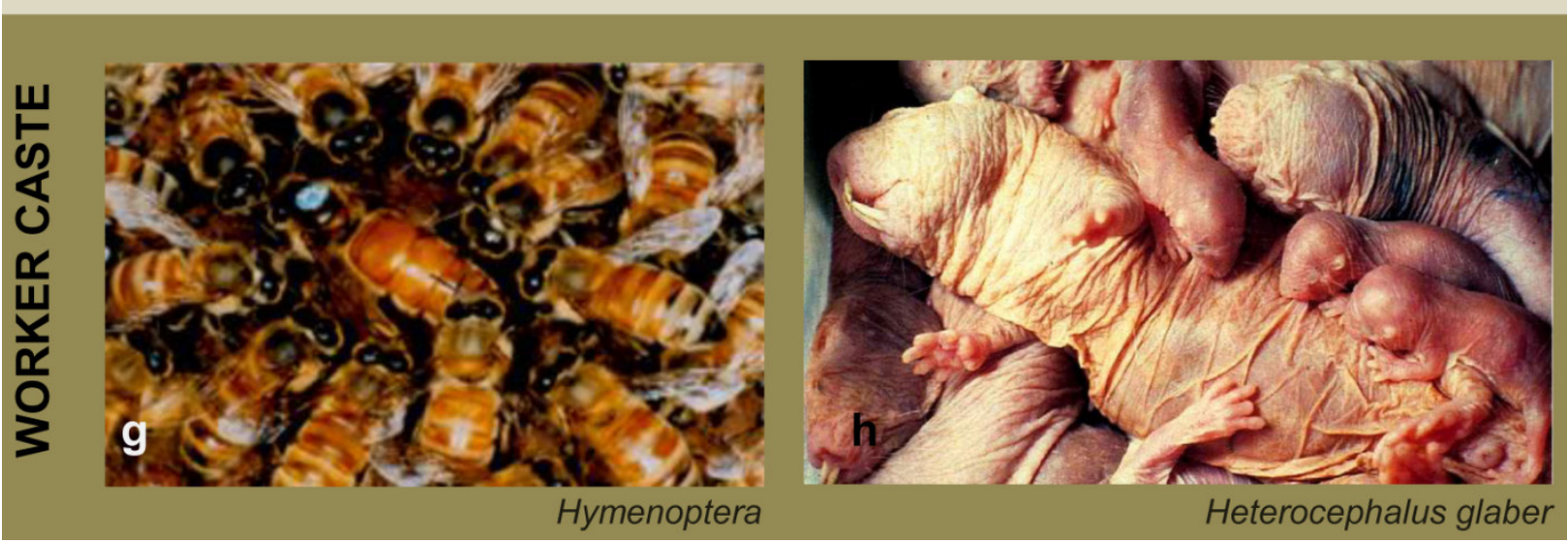

Figure I. The worker and soldier castes in eusoical societies. a. Termite soldier (upper right) and workers from the genus Nasutitermes (Photo Credit: Alex Wild). b. The soldier (left) and worker (right) castes of the Nevada dampwood termite, Zootermopsis nevadensis (Photo Credit: Li Tian). c. The soldier caste (right) in a trematode, Himasthla spp. (Image Source: Hechinger et al ${ }^{[173]}$ ). d. A soldier of Tuberaphis styraci, a eusocial aphid, fights against its natural enemy, a predatory lacewing larva (Image Source: Shibao et al ${ }^{[13]}$ ). e. The soldier (right) and worker (left) castes in a stingless bee, Tetragonisca angustula (Image Source: Gruter et al ${ }^{[15]}$ ). f. Major (left) and minor (right) workers of Pheidole barbata, a small harvester ant (Photo Credit: Alex Wild). g. A queen surrounded by the workers in a honey bee, Apis merllifera, colony (Image Source: Beggs et al ${ }^{[174]}$ ). h. Queen (center), worker (upper right) and young brood in a naked mole rat, Heterocephalus glaber, colony (Image Source: gardenofeaden.blogspot.com). 
Extensive studies of life history, function and caste regulation in eusocial hymenopterans shed light on the ultimate and proximate mechanisms underlying the evolution and maintenance of eusociality $[2,4$, 12, 20-22]. Soldier-first lineages, which exhibit substantial differences from the worker-first Hymenoptera [10, 23-25], provide alternative and complementary models for the comprehensive understanding of the evolution of eusociality [6, 26, 27]. In this review, we present an up-to-date summary of our current knowledge regarding the soldier caste. We define the soldier caste as individuals that possess no or reduced reproduction and that are both morphologically and behaviorally specialized for defense. This excludes old workers that may defend the nest (also called temporal soldiers) in bees and wasps [28-30]. Our primary focus is the bona fide soldier caste in soldier-first eusocial lineages, which evolved directly from the reproductive form $[17,31,32]$. We do include the physical soldiers in ants throughout this review because of their morphologically and behaviorally specializations for defense [4]. Although it is still debatable whether ant soldiers evolve from reproductives in a way that parallel to, yet independent from workers ( e.g. most researchers believed that ant soldiers evolved from worker caste) [33-37], ant soldiers apparently represent convergent evolution between ants and termites under similar ecological conditions [4]. To facilitate future research, questions regarding the ecological and evolutionary significance of the soldier-first eusociality are discussed as well.

Table I. The soldier caste in different eusocial lineages.

\begin{tabular}{|c|c|c|c|c|c|c|}
\hline Lineage & Origina & Stageb & Sexc & Function & Representative Species & Reference \\
\hline shrimp & $\mathrm{R}$ & $\mathrm{A}$ & $\mathrm{M}$ & Defense & Synalpheus regalis & [8] \\
\hline \multirow[t]{3}{*}{ Aphid } & $\mathrm{R}$ & $\mathrm{J}$ & $\mathrm{F}$ & Defense & Tuberaphis styraci & [175] \\
\hline & & & & Colony hygiene & Pemphigus spyrothecae & [63] \\
\hline & & & & Nest repair & Pemphigus spyrothecae & {$[64]$} \\
\hline \multirow[t]{2}{*}{ Thrip } & $\mathrm{R}$ & A & $M \& F$ & Defense & Oncothrips tepperi & [32] \\
\hline & & & & Antifungal agent & Kladothrips intermedius & [66] \\
\hline \multirow[t]{6}{*}{ Termite } & $\mathrm{R}$ & $\mathrm{J}$ & $M \& F$ & Defense & Coptotermes formosanus & [176] \\
\hline & & & & Antifungal agent & Nasutitermes costalis & [177] \\
\hline & & & & Scout & Nasutitermes costalis & {$[68]$} \\
\hline & & & & Egg transferring & Prorhinotermes simplex & [72] \\
\hline & & & & Caste regulation & Reticulitermes flavipes & [127] \\
\hline & & & & Reproduction & Zootermopsis nevadensis & [75] \\
\hline \multirow[t]{5}{*}{ Hymenopterad $^{d}$} & We & A & $\mathrm{F}$ & Defense & Pheidole bicarinata & [178] \\
\hline & & & & Nurse & $\begin{array}{l}\text { Pheidole megacephala } \\
\text { megacephala }\end{array}$ & [179] \\
\hline & & & & Seed milling & Solenopsis geminata & [180] \\
\hline & & & & Food storage & Colobopsis nipponicus & [62] \\
\hline & & & & Tropical egg laying & Crematogaster smithi & [167] \\
\hline
\end{tabular}

"a": evolutionary origin of the soldier caste.

" $b$ ": the developmental stage of the soldier caste.

"c": sex of the soldier caste

" $\mathrm{d}$ ": only include the physical soldier caste in ants here

"e": Ant soldier is origined from either reproductives or worker. R: Reproductive form, W: Worker caste, A: Adult, J: Juvenile, M: Male, F: Female.

\section{The soldier caste}

\section{What constitutes a soldier?}

Soldier-first eusociality is not uncommon across phylogenetically distant taxa. In termites, the soldier caste represents a final developmental stage (Table 1) [38]. They differentiate from juveniles through molting and the final stage is always preceded by a pre-soldier stage [39]. These soldiers are considered as permanent juveniles because their prothoracic glands do not degenerate during morphogenesis [40]. In eusocial aphids, the soldier caste maybe $1^{\text {st }}$ or $2^{\text {nd }}$ immature instars, depending on the species (Table 1) [17]. These aphids either never molt or remain instars for a prolonged time period before developing into adults [41]. Caste determination takes place during embryonic development or at a late $1^{\text {st }}$ instar stage [41-43]. In social thrips, the soldiers are adult male or female offspring of the foundress (Table 1) [6, 44]. Caste determination seems to occur in the egg [45]. In the eusocial snapping shrimp of the genus Synalpheus, soldiers are large, mature males with powerful major chelae, which defend the queen and juveniles against hetero/ conspecific intruders (Table 1) [8, 46, 47].

Besides soldier-first lineages, physical soldiers have been documented in few Hymenoptera lineages (Table 1). In ants with a polymorphic worker system, a major worker is commonly called "soldier" because of its morphological and behavioral specialization for defense [33, 34]. Most recently, a physical soldier caste was discovered in a neotropic stingless bee, Tetragonisca angustula, [15]. The body size of the soldier bees is larger than foragers and they are specialized for nest defense. 
Interestingly, a physical soldier caste is also documented in non-eusocial animals. A trematode speices (Himasthla sp.), which infects the California horn snail, Cerithidea californica, produces two morphologically distinct forms, a soldier morph and a reproductive morph, within the host $[7,22]$. The soldier morph defends the reproductive morph against interspecific competitors within the same host [48, 49]. A physical soldier caste is also documented in a polyembryonic wasp, Copidosoma floridanum (Encyrtidae), during its larval stage inside the host [50]. In this species, females lay eggs in the host, and the subsequent embryonic proliferation produces about 3000 embryos [51, 52]. Most embryos develop into larvae that will eventually develop into adults, while a small portion develops into "soldier" larvae [51]. These soldier larvae defend siblings against competitors but are not able to develop beyond the larval stage, and die from desiccation after the host is consumed [53,54].

\section{Morphological distinctions of the solider caste}

Anatomical specialization for defense is a typical trait of a soldier caste (Fig.1). In social aphids, a soldier usually possesses an enlarged body, sclerotized tergites and stylets, enlarged forelegs or sharp frontal horns, which are adaptations to attack Dipteran or coleopteran predators (Fig. 1d) [41]. In gall-dwelling thrips, the soldier caste possess reduced wings (micropterous) and armed forelegs [6, 55], making them efficient defenders against predators and kleptoparasitic thrips (gall-stealing species of Koptothrips) [32]. Termite soldiers have various physical modifications for nest defense $[16,38]$. Soldiers in all termite lineages possess heavily sclerotized and pigmented head capsules, which are stronger than those of workers and reproductive (Fig. 1a,b) [38]. In some lineages, soldiers possess enlarged mandibles that are used to attack intruders by biting, crushing and slashing (Fig. 1b) [56]. This morphological adaptation enables soldiers to fight and kill equal sized competitors and predators, such as ants. In genus Nasutitermes, soldiers possess an ampule-shaped head capsule that houses the frontal gland to eject toxic terpenoid chemicals (Fig. 1a) [56]. In genera Cryptotermes [57] and Reticulitermes [58], the size and shape of soldier head are adapted for phragmosis defense (blocking the nest entrance to prevent invaders from entering the nest) [56]. Snapping shrimp soldiers are larger than nest mates in body size and possess powerful major chelae $[8,46,47]$. When faced with an intruder, the soldier shrimp aggressively snaps at the enemies until they are killed or expelled from the nest.

In comparison to soldier-first lineages, a physical soldier caste is limited in worker-first lineages, which exists predominantly in few ant species with elabo- rated morphological specializations [4]. In the ant genera Pheidole and Solenopsis, soldiers possess a large body size and a disproportionately enlarged head (Fig. 1f) [19]. These traits are likely adaptations for fighting or phragmosis defense [59]. Soldiers in the genus Eciton possess large, fishhook-shaped mandibles, which are believed to be effective weapons against vertebrates $[4,60]$. Some species in the genera Pheidole, Solenopsis, and Camponotus, are trimorphic within the worker caste, such that soldiers can be of multiple sizes and are subdivided into "small" and "super" soldiers [61]. In stingless bee, Tetragonisca angustula, the soldier caste is bigger, heavier and has larger hind legs in comparison to regular workers, which enable them to carry out effective nest defense (Fig.1e) [15].

The soldier morph of trematode is smaller and possesses much larger mouthparts than the reproductive morphs $[48,49]$. The enlarged mouthparts facilitate their fighting with conspecific intruders, while the smaller body size can enhance defensive functionality by facilitating dispersion of soldier morphs through the host tissue [48, 49]. In polyembryonic wasp C.floridanum, soldier larvae possess elongate body and are equipped with specialized fighting mandibles, which enable them to fight with inter-clonal competitors [53].

\section{Adaptive functions of the solider caste}

Besides nest defense, the soldier caste in many eusocial lineages has evolved various adaptive functions (Table 1). In many ant species, soldiers may participate in seed milling, food storage and even brood care, in addition to nest defense [2, 59, 62]. Soldiers from social aphids are actively involved in gall cleaning and repair [17, 63, 64]. These individuals eliminate defecated honeydew, shed skins and carcasses, and also repair gall openings that are damaged by predators [63]. Soldiers within gall-dwelling thrips could lay eggs and produce dispersers $[45,65]$. Hence they contribute to colony reproduction, despite that they have reduced fecundity when compared to the foundress [45]. A recent study found that soldiers of the social thrip, Kladothrips intermedius, perform an antifungal function by secreting specific compounds to control the fungal pathogen Cordyceps bassiana [66]. In termites, soldiers of Nasutitermes costalis may control the growth of a nest microbe by releasing terpenoid secretions from their frontal gland [67]. Termite soldiers, sometimes, also serve as foraging scouts [68-71]. This task is considered an adaptation of the soldier caste to reduce predation risk in the early phase of foraging activities, during which nest members are more likely to be exposed to other predators [68]. Soldiers of Prorhinotermes simplex participate in the transportation of eggs after the colony is disturbed 
[72]. Moreover, the soldier caste in some termite species also contributes to colony reproduction. High numbers of soldiers have been observed to accompany and protect alates, thereby assisting the swarm [73]. The presence of soldiers also appears to stimulate the production of supplementary reproductives [38, 73], a process which is associated with the juvenile hormone (JH) [38, 74]. According to Henderson [38], termite soldiers act as a "JH sink" that uptakes $\mathrm{JH}$ from nest mates during the caste transition process to decrease the JH level of the reproductively competent immature workers [38]. In some basal termite families (e.g., Termopsidae), there is a fertile soldier caste in addition to the regular soldiers [75]. This soldier caste, by itself, is a reproductive caste. Fertile soldiers possess defensive morphology and, in the meantime, they also have well-developed gonads and are capable of egg-laying [75].

\section{Soldier caste transition}

\section{What is the cost of maintaining a soldier caste?}

In most eusocial lineages, the physical soldier caste is costly to produce and maintain [4, 38, 43]. Termite soldiers are unable to collect food and must depend on the assistance of workers for food $[38,76]$. Overloading of soldier caste, i.e., maintaining a higher than normal soldier percentage in a colony, adversely impacted the survivorship of the termite colony [14]. In ants, production of soldiers requires a high level of nutrition to be received by the brood [4, 77]. In social aphids, the production of soldiers can slow down the intrinsic growth rate of the colony [56]. In comparison to a temporal based caste system, the morphology-based caste is less flexible in modulating caste compositions in response to environmental cues [4, 78]. This is one of the reasons that most hymenopterans employ temporal-based nest defense (age-dependent polyethism) as opposed to a physical soldier caste [78]. To maximize colony fitness in face of a trade-off between enhanced defense and soldier maintenance, eusocial lineages must regulate soldier production in response to various environmental cues to ensure adequate defensive capability while minimizing fitness costs $[13,48,79]$.

\section{Epigenetic factors}

Various environmental cues have been documented to affect the regulation of soldier caste in soldier-first lineages. These cues can influence colonial decisions in soldier production and allocation by affecting both the necessity of defensive investment and the level of available resources for defensive investment. Predation and competition could increase the colonial demand for soldier investment. Shibao [80] hypothesized that production of soldiers should be responsive to the level of predation or competition risk to optimize colony fitness. Consistent with this "optimized defense" hypothesis, studies in diverse lineages show that soldier production and allocation could be affected by environmental factors. Direct risk of predation and competition, which is caused by the presence of predators and competitors, can prolong the soldier instar in social aphids [81], and increase the production of the soldier caste in ants [79] and polyembryonic wasps, C. floridanum [82]. Indirect risk which is represented by the likelihood of encourtering predation or competition, can also affect soldier production. In the aphid Pseudoregma sundanica, ant tending can inhibit the production of sterile soldiers [83]. Excluding ants from a P. sundanica colony, causes a loss of protection agaist predators and represents a higher predation risk, thereby resulting in increased soldier production [83]. Similarly, the social trematode (Philophthalmus sp.) produces fewer soldiers when the trematode parasitizes larger host snails, which are less likely to be co-infected with other competing trematodes [48]. Seasonal or temperature changes, which could affect predator abundance, may affect soldier production in termites and aphids. In a subterrenan termite, Reticulitermes flavipes, the percentage of soldiers reaches its peak in the spring when temperatures are increasing, which is advantageous for the protection of emerging alates $[14,38]$. In the bamboo aphid, P. bambucicola, soldier percentage in a colony started to increase in late summer, reached a peak in autumn, and then abruptly decreased in early winter [84].

The abundance and/or spatial distribution of predators and competitors can also affect the distribution of soldiers within a colony. Social societies allocate their soldier caste to regions in which predation and competition risks are high $[68,69,80]$. In $P$. bambucicola, soldier distribution was biased toward peripheries that are exposed to predators [80]. In termites, soldier density was substantially greater during the exploratory phase of foraging in unknown territories where a higher risk of intra- or inter-specific confrontations was present [68, 69, 85]. Interestingly, when the Eastern subterranean termite, $R$. flavipes, encountered corpses from a congeneric competitor, $R$. virginicus, significant more $R$. flavipes soldiers were recruited to the burial site in comparison to the treatment with $R$. flavipes corpses [86].

Other epigenetic factors, including colony size and population density, can also affect the soldier production $[87,88]$. In two social aphid species, Tuberaphis styraci and Pseudoregma bambucicola, increased colony size is consistently associated with higher soldier ratio [88, 89]. A similar correlation has been documented in carpenter ant species Camponotus no- 
vaeboracensis [90]. In T. styraci, soldier production can be affected by the population density in a colony [43]. In addition, under specific environmental conditions, the soldier ratio seems to be consistently different among genetically unrelated laboratory $R$. flavipes colonies, suggesting that genetic factors may also play a role in the soldier production [91]. Recently, several studies have focused on how reproductives affect the soldier production in the soldier-first lineages. In the worker-first Hymenoptera and naked mole rats, the presence of the queen could suppress the production of new queens or inhibit worker reproduction, through physical aggression or queen pheromone [92-97]. In the soldier-first lineages, the presence of primary or secondary queens has been shown to inhibit the differentiation of new reproductive [98-100], while facilitate soldier differentiation in termites [101-103]. Interestingly, the soldier caste in lower termites seems to regulate queen production by controlling $\mathrm{JH}$ level of nestmates through an unknown mechanism [38]. Future study is needed to explore queen-soldier interactions in the soldier-first lineages.

\section{Resource availability and allocation}

The abundance and quality of food resources are closely associated with soldier abundance. Since development and maintenance of this caste are energetically costly, soldier investment is favored when a colony is nutritionally sound [104, 105]. In a subterranean termite, Coptotermes formosanus, soldier production took place when workers received a high-nutritional food (e.g. pine wood) instead of a low-nutritional food (e.g. filter paper) $[105,106]$. A mathematical model [107] showed that food availability and allocation can affect soldier production in lower termites. Based on the model, soldiers are produced from young workers when food is abundant, and are produced from older workers when food is scarce [107]. Resource availability can also affect soldier production in ants, in which high quality food (a high protein diet) is believed to be essential for the development of soldiers from larval ants [77, 108-111].

\section{Regulation of soldier caste differentiation}

\section{Regulatory mechanisms}

Juvenile hormone (JH), an important growth hormone in insects, has been implicated in caste determination and division of labor [112-114]. In termites, $\mathrm{JH}$ is essential for soldier caste differentiation and is responsive to environmental cues, including nutrition, temperature and seasonality [105, 115]. It has been demonstrated in many different species that $\mathrm{JH}$ induces worker-soldier transition [116-119], in which externally applied $\mathrm{JH}$ or a $\mathrm{JH}$ analog (JHA) stimulated pre-soldier formation in termites [113,
120-122]. A similar association between JH and soldier production has been found in eusocial Hymenoptera. Topical application of $\mathrm{JH}$ or methoprene (a JH analog) on larval ants promotes the development of the soldier morph in several ant species $[78,123,124]$.

Besides JH, soldier caste differentiation appears to be self-regulated through positive and negative feed-back mechanisms in termites [38, 125], aphids [43] and ants [110]. In termites, soldiers dictate its own percentage by inhibiting worker-soldier caste differentiation through down-regulating of $\mathrm{JH}$ titer in workers [38, 120, 125]. In addition, pheromones might also play a role in the self-regulation process. Lefeuve [125] suggested that soldier differentiation in a higher termite, Nasutitermes lujae, might be inhibited by a contact pheromone secreted from the frontal glands of soldiers. Consistent with this hypothesis, two soldier-produced terpenes, $\gamma$-cadinene (CAD) and $\gamma$-cadinenal (ALD) have recently been extracted from the soldier head of $R$. flavipes. These soldier head extracts, serving as primer pheromones modulating the $\mathrm{JH}$ response threshold in workers, clearly exhibited regulatory effects on soldier differentiation [126, 127]. Similarly, ant soldiers may also regulate the JH level of their nestmates. Modulation occurs during the larval stage, possibly through an inhibitory soldier pheromone, which can be transferred though brood feeding [110]. In the aphid Tuberaphis styraci, physical contact seems to be important in self-regulation [42]. Frequent physical contact among non-soldier nymphs due to crowding can trigger soldier differentiation [42]. On the other hand, the "coexisting" soldiers can suppress the soldier differentiation $[42,43]$.

\section{Molecular basis}

The molecular basis underlying the soldier caste differentiation has been investigated in termites, and several genes and regulatory pathways have been implicated in the worker-soldier transition in termites. SOL1, a soldier specific gene in the Japanese damp-wood termite, Hodotermopsis japonica, is expressed exclusively in terminally differentiated soldiers but not in presoldiers [39]. It is believed that SOL1 is one of the most downstream genes in the cascade because the expression of SOL1 begins after caste differentiation is completed [39]. A recent study identified another soldier specific gene, $\mathrm{Hsj} \mathrm{Cib}$, in the Japanese rotten-wood termite Hodotermopsis sjostedti [128]. This gene, categorized as a $\beta$-thymosin, encodes an actin binding protein. It is considered as a potential downstream effector in the soldier morphogenesis and is likely involved in cephalic morphogenesis and neural reorganization. Hexamerins, a family of storage proteins, have been shown to play an essential role in the regulation of soldier differentiation in termites. 
Downstream pleiotropic effects caused by hexamerins silencing significantly affect the expression of soldier morphogenesis-associated genes [117] and eventually induce JH-dependent presoldier formation [129]. These mechanistic studies indicate that hexamerins possess $\mathrm{JH}$-sequestering capabilities and can regulate worker-soldier transition by modulating the availability of JH [129]. As a negative regulator, hexamerins are also responsive to environmental stimuli, including epigenetic factors such as temperature and nutrition [117] as well as predation and competition stress (Li and Zhou, unpublished data), which, in turn, influence the downstream soldier formation. These combined findings suggest that the hexamerins are one of the environmentally responsive factors that exert a regulatory function by connecting upstream epigenetic factors to downstream caste differentiation responses [117].

Recently, it has been demonstrated that soldier morphogenesis is associated with the insulin/insulin-like growth factor signaling (IIS) pathway in the termite $H$. sjostedti [130]. Termite orthologs of the IIS pathway, including $H s j I n R, H s j P K B / A k t$, were up-regulated during soldier morphogenesis [130]. It is believed that insulin signaling could interact with $\mathrm{JH}$ and may play an important role in mandible elongation during soldier formation [130].

\section{The evolution of soldier caste}

Distinctively different caste distributions have been observed in worker-first and soldier-first lineages. A physical soldier caste is not common in worker-first lineages, and have only been documented in a few ant species, and recently in a stingless bee T. angustula $[4,78]$. On the other hand, the presence of a true worker caste is not common in soldier-first lineages, and has only been documented in several termite families [40]. The distinct caste distribution between worker-first and soldier-first lineages strongly suggests functional tradeoffs between these two groups during the eusocial evolution (e.g. improved brood care for worker first lineages and enhanced colony defense for soldier-first lineages) [10, 18]. It also suggests that the evolution of eusociality in these two groups could be driven by different biological, ecological, and genetic factors [10, 18, 26, 131].

\section{Biological factors}

Caste determination is inevitably affected by the distinctively different developmental pathways, including the holometabolous hymenopterans and the hemimetabolous termites. Metamorphosis can affect the evolution of the worker caste via immature dependency. The holometabolous development in Hymenoptera creates highly dependent larval instars, and such dependency is believed to promote the evolution of workers [25]. The extensive brood care required by highly dependent larvae may encourage the evolution of alloparenting. For example, social Hymentoptera are evolved from solitary lineages exhibiting extensive brood provision for helpless young [10]. By contrast, the hemimetabolous termites produce relatively independent immature instars [25, 132]. These immatures are, by themselves, capable laborers to carry out various tasks for the colony. In comparison to the holometabolous hymenopterans, evolving specialized workers for brood care might not be the top priority in the hemimetabolous termites. Indeed, true workers are, generally, absent in the primitive termites [24, 132].

The evolution of a distinct physical soldier caste is not common in the holometabolous Hymenoptera. Holometabolous hymenopterans typically reach the maturation at the adult stage with limited developmental flexibility. To maintain an optimum caste composition, a holometabolous colony would have to precisely anticipate environmental changes to adjust larval development, which would be difficult in a consistently changing environment [4]. Camponotus impressus, a plug-headed ant species, was seen to produce constantly low ratio of soldier to worker in new brood regardless of variation in resource, competition and predation. Therefore the species exhibits limited ability to adjust its soldier ratio in response to environmental variations by producing new ants [133]. In contrast, hemimetabolous termites consist of a series of immature instars retaining developmental plasticity [4]. These totipotent immatures can differentiate into various physical castes depending on the colony needs [38]. Consequently, physical caste adjustment does not require production of new brood, but can be achieved through caste differentiation among existing colony members. Hemimetabolism therefore leads to a greater flexibility in the development of a physical caste system. Especially, in lower termites, the soldier caste can be developed from multiple immature stages [134].

In addition, the morphological peculiarity can also impact the evolution of physical castes. It is believed that species that are anatomically well-equipped for defense might not need a highly specialized soldier caste, including social hymenopterans which possess hard exoskeletons, stings or toxic glands $[4,18]$. The sting, in particular, might be an adequate defense mechanism to replace a bona fide soldier caste $[4,18]$. In contrast, termites and aphids are both soft-bodied insects that possess few, if any, defensive structures. Therefore, the evolution of a defensive caste would greatly improve the overall colony fitness. This tradeoff has been observed in a 
stingless bee, Tetragonisca angustula, in which the reduced sting is attributed to the presence of anatomically distinct guard bees [15].

\section{Ecological factors}

Ecological factors, such as nesting structure/habitat can have profound influence on the evolution of castes. By dwelling and feeding inside their nest, foraging is not necessarily required for the soldier-producing lineages, suggesting that evolution of foragers might not be essential in these lineages [25]. In some basal termite species, which nest in a single piece of wood log for their lifetime, true workers are absent [25]. By contrast, true worker caste does evolve in termite species nesting in separate locations, in which foraging outside the nest is mandatory [40]. In addition, saturated nesting site, limited resource, and high predation and competition pressure demand effective defensive strategies [135-137], which can lead to the evolution of distinct soldier caste [10]. In social aphids, predation risk seems to be the primary driving force for the evolution of soldier caste [89, 138]. Intraspecific competition likely drives soldier evolution in termites [75], snapping shrimps [139], and social trematodes [49]. Similarly, interspecific parasitism is thought to be the main driving forces for the evolution of the soldier caste in social thrips [32].

In contrast, most social hymenopterans have strong flight capability and have the tendency to explore new territories [10, 25]. This would free the Hymenoptera lineages from strong local competition for nesting sites. In addition, Foraging outside the nest is required for colony survival, which may lead to the evolution of foragers in social hymenopterans [10]. The convergent evolution between ants and termites reflects the ecological influences on the evolution of distinct castes $[4,25]$. With a subterranean nesting structure similar to termites, predation and completion stress may select for the evolution of a distinct soldier caste in some ant species [79, 140,141]. On the other hand, termite species with separated nesting structures and consistently foraging outside the nest may contribute to the evolution of a true worker caste in these lineages [40,142].

\section{Genetic factors}

Debates over the contribution of genetic relatedness to the evolution of altruistic caste have been ongoing for many years [21, 23, 143-146]. Currently, the controversy seems to lie in whether close kinship is a driving factor or merely a consequence of the evolution eusociality $[147,148]$ and whether ecological factors or genetic factors contribute more in shaping eusociality [149-154]. In Hymenoptera, the haplodiploid genetic system results in higher genetic re- latedness of workers to females (siblings) than to males (brothers and sons) [21, 22]. Supporting kin selection theory [21], workers seem to favor raising the most related full siblings than less related males, leading to a female-biased sex ratio in a colony [22, $155,156]$.

Most soldier-first lineages are diploid animals. The sex ratio theory based on asymmetric relatedness does not seem to apply to these lineages [18, 145, 157]. Nevertheless, a high level of genetic relatedness has been assumed in many soldier-first lineages, because of their reproductive strategies and lifestyle [10, 18, 157]. For example, in social aphids, colony members can be genetically identical due to clonal reproduction. In termites, high genetic relatedness is achieved through monogamy [158], inbreeding [159] and chromosomal translocations [160]. In addition, high genetic relatedness via inbreeding has also been documented in social thrips [161, 162]. Recently, Kobayashi et al [150] documented a mother-son inbreeding system in two Reticulitermes species, $R$. virginicus and $R$. speratus. This asymmetric genetic system indicates that colony members are more related to the queen (female) than they are to the king (male). In agreement with kin selection theory, reproductive alate populations were found to be strongly female biased in colonies with mother-son inbreeding, suggesting that colony members favor the sex to which they are more related [150].

Despite the clear contribution from genetic factors, studies on soldier-first lineages implicate the significance of biological and ecological factors in shaping the evolution of an altruistic caste [151-154]. First, some soldier-first lineages exhibit no clear correlation between genetic system and sex ratio bias. The gall-dwelling thrips, for instance, is the only haplodiploid soldier-first lineage. Unlike female-biased Hymenoptera colonies, soldier thrips could be of both sexes [6]. The same is true of the eusocial ambrosia beetle, Austroplatypus incompertus [7]. Being diploid, workers of the beetle are all female [7]. Herrera [145] recently argued that a high degree of inbreeding might override the haplodiplody in eusoical thrips, making both sexes close related, and that the eusoical beetle $A$. incompertus might be derived from a haplodiploid ancestor. However, this hypothesis remains to be tested by future studies. In addition, many soldier-first lineages might not possess high genetic relatedness. Colony fusion, which could decrease of the genetic relatedness between nest mates, has been reported in termites [163] and aphids [164]. Inbreeding within termite species is believed to be less frequent than previously assumed [154]. Furthermore, empirical studies suggest that the soldier caste of some social aphids lacks kin discrimination; 
hence they lack the behavioral basis for kin selection $[151,152,165]$.

Although the correlation between genetics and the development of altruistic castes has been extensively studied, few efforts have focused on how genetic factors contribute to distinct caste evolution among eusocial lineages. Yamamura [18] developed a model of genetic correlation with caste distribution. Comparative study of social aphids, termites and Hymenoptera suggested that genetic identity based on clonal reproduction could favor the evolution of a soldier caste [18]. Diploid system could allow the evolution of both workers and soldiers. Haplodiploidy could favor the evolution of only workers [18]. However, this model seems to be based on an over-simplified analysis that did not incorporate other factors that may be important for caste evolution. In addition, the suggested genetic correlations of caste distribution failed to explain caste system in more recently discovered eusocial lineages such as social thrips (haplodiploid, with only soldiers) [32], eusocial beetles (diploid, with only workers) [7], naked mole rats (diploid, with only workers) [9] and snapping shrimps (diploid, with only soldiers) [8].

\section{Perspectives and questions}

\section{How to define a soldier caste?}

The term "soldier caste" implicates the primary adaptation of this caste as nest defense. However, soldier castes in some lineages can perform other adaptive functions [17, 63, 66, 72]. In some cases, soldiers do not carry out defense at all. A soldier caste that carry out no defense is known in many ants species $[2,166,167]$, where they may be adapted for other function [4]. Although controversial [153, 168], Myles [169] suggested that the morphology of termite soldiers might originally be adaptations for neotentic competition for nest inheritance and breeding position. Recent discovery of anti-fungal function in the gall-dwelling thrips K. intermedius [66] suggests that fugal pathogens might be major selective factors for soldier evolution in social thrips [66]. These findings suggest that ecological factors other than defense might be involved in shaping the evolution of the soldier caste. It is also possible, that soldier castes in some lineages is primarily adapted for other function with nest defense being subsequently formed. Therefore, future efforts should focus on exploring the function of the soldier caste in each lineages, since such information would undoubtedly lead to deeper insights into the evolution of soldier caste and eusociality.

In addition, questions may arise when the term "soldier" is used to describe the sterile caste in some lineages without knowing whether the caste is truly specialized for nest defense. In ants, the term "soldier" is used to describe wingless caste that are neither workers nor reproductives and that possess limited task repertoire, regardless whether the individual carry out nest defense [167, 170]. However, we suggest precautions in the use of "soldier" in the soldier-first lineages [4]. Since the "soldier" is the first specialized sterile caste in these lineages, functions of this sterile caste, which is directly reflected by its name, may directly indicate ecological implications in eusocial evolution of these lineages [4]. Therefore, use of "soldier" to define these sterile castes without comprehensive understating of their adaptive functions would mislead our understanding of eusoical evolution in these lineages.

\section{The relative importance of ecological and genetic factors in shaping caste function}

Despite the fact that both soldiers and workers exhibit reproductive altruism, the two castes are distinct in their adaptive functions. Current debates regarding how genetics and ecological factors contribute to the development of eusociality primarily focus on how these factors contribute to the evolution of altruistic helping(why to help), whereas the remarkable functional differences (how to help) between the two castes are not sufficiently considered. Although it has been demonstrated in many lineages that genetic relatedness might contribute to evolution of altruism in both worker-first and soldier-first lineages, little genetic correlation has been found to explain distinct caste distribution in worker-first and soldier-first lineages. However, a comparison between worker-first and soldier-first lineages suggests the presence of strong ecological and biological correlations for such differences. Therefore, while eusocial evolution could be attributed to both genetic and ecological factors, the function and distribution of altruistic castes are primarily shaped by the latter.

\section{Soldier-derived eusociality}

Classical theories on eusocial evolution and maintenance, such as kin selection, primarily focus on the sterile worker caste in the social Hymenoptera [2, 21]. However, the discovery of soldier-first lineages suggests that social evolution could take place under very different genetic and ecological conditions and can take different forms (soldier first eusociality versus worker first eusoicality). Furthermore, the discovery of a physical soldier caste in trematodes and parasitic wasps indicates that a distinct altruistic caste can also be present in non-eusocial systems, as long as biological and ecological factors essential for caste evolution are met. Therefore, study on the soldier 
caste and soldier-first lineages have led to new insights into the evolution of caste and eusociality. More importantly, the soldier-first lineages provide important complementary additions to comparative models available for study social evolution, because of their distinct biological and ecological traits. Despite a growing interest in the study of soldier castes $[66,130,150,167,171]$, the evolution and regulation of soldier caste in eusocial lineages remains unclear. For instance, it is still unknown how JH and/or pheromone regulate soldier caste differentiation in snapping shrimps, gall-dwelling thrips or eusocial aphids. Although few studies have focused on the molecular mechanisms of caste differentiation in termites [39, $117,128,129]$, the ultimate and proximate factors contributing to the soldier differentiation are far from clear [18, 75, 153, 172]. Empirical study is, therefore, warranted to explore the function, evolution and regulation of the soldier caste.

\section{Acknowledgements}

The authors are grateful to five anonymous reviewers and the editor for their constructive criticisms. Special thanks go to Drs. John Obrycki, Kenneth Haynes and Janet Lensing (Department of Entomology, University of Kentucky) for their comments on the manuscript. This research was supported by a start-up fund from the University of Kentucky, a grant from the Kentucky Commercialization Fund Program, Kentucky Science and Technology Corporation (Award Agreement No. KSTC-144-401-09-034), and the Research Support Grant Program sponsored by the University of Kentucky Office of the Vice President for Research. The granting agencies have no role in the study design, data collection and analysis, decision to publish, or preparation of the manuscript. The information reported in this paper (No. 13-08-082) is part of a project of the Kentucky Agricultural Experiment Station and is published with the approval of the Director.

\section{Competing Interests}

The authors have declared that no competing interests exist.

\section{References}

1. Szathmary E, Smith JM. The major evolutionary transitions. In: Gee H, ed. Shaking the Tree: Readings from nature in the history of life: University of Chicago Press; 2000: 32-47.

2. Wilson EO. The insect societies. Cambridge, Mass: Harvard University Press; 1971.

3. Crozier RH, Pamilo P. Evolution of social insect colonies: sex allocation and kin selection. Oxford: Oxford University Press; 1996.

4. Oster GF, Wilson EO. Caste and ecology in the social insects. Princeton, NJ: Princeton University Press; 1978.

5. Stern DL, Foster WA. The evolution of sociality in aphids: a clone's-eye view. In: Choe JC, Crespi BJ, ed. The evolution of social behavior in insects and arachnids Cambridge University Press, Cambridge; 1997: 150-65.

6. Crespi BJ. Eusociality in Australian gall thrips. Nature. 1992; 359(6397): 724-6.
7. Kent DS, Simpson JA. Eusociality in the beetle Austroplatypus incompertus (Coleoptera: Curculionidae). Naturwissenschaften. 1992; 79(2): 86-7.

8. Duffy JE. Eusociality in a coral-reef shrimp. Nature. 1996; 381(6582): 512-4.

9. Jarvis J. Eusociality in a mammal: cooperative breeding in naked mole-rat colonies. Science. 1981; 212(4494): 571-3.

10. Queller DC, Strassmann JE. Kin selection and social insects. Bioscience. 1998; 48(3): 165-75.

11. Bourke AFG, Franks NR. Alternative adaptations, sympatric speciation and the evolution of parasitic, inquiline ants. Biol J Linn Soc. 1991; 43(3): 157-78.

12. Smith CR, Toth AL, Suarez AV, Robinson GE. Genetic and genomic analyses of the division of labour in insect societies. Nat Rev Genet. 2008; 9(10): 735-48.

13. Shibao H, Kutsukake M, Matsuyama S, Fukatsu T, Shimada M. Mechanisms regulating caste differentiation in an aphid social system. Commun Integr Biol. 2010; 3(1): 1-5.

14. Haverty M, Howard R. Production of soldiers and maintenance of soldier proportions by laboratory experimental groups of Reticulitermes flavipes (Kollar) and Reticulitermes virginicus (Banks)(Isoptera: Rhinotermitidae). Insect Soc. 1981; 28(1): 32-9.

15. Gruter C, Menezes C, Imperatriz-Fonseca VL, Ratnieks FL. A morphologically specialized soldier caste improves colony defense in a neotropical eusocial bee. Proc Natl Acad Sci U S A. 2012; 109(4): 1182-6.

16. Prestwich GD. Chemical defense by termite soldiers. J Chem Ecol. 1979; 5: 459-80.

17. Stern DL, Foster WA. The evolution of soldiers in aphids. Biol Rev Camb Philos Soc. 1996; 71(1): 27-79.

18. Yamamura N. Different evolutionary conditions for worker and soldier castes: genetic systems explaining caste distribution among eusocial insects. J Theor Biol. 1993; 161(1): 111-7.

19. Hölldobler B, Wilson EO. The superorganism: the beauty, elegance, and strangeness of insect societies. New York: WW Norton \& Company; 2009.

20. Beshers SN, Fewell JH. Models of division of labor in social insects. Annu Rev Entomol. 2001; 46(1): 413-40.

21. Hamilton WD. The genetical evolution of social behaviour, I \& II. J Theor Biol. $1964 ; 7: 1-52$

22. Trivers RL, Hare H. Haploidploidy and the evolution of the social insect. Science. 1976; 191(4224): 249-63.

23. Nowak MA, Tarnita CE, Wilson EO. The evolution of eusociality. Nature. 2010; 466(7310): 1057-62

24. Korb J, Buschmann M, Schafberg S, Liebig J, Bagnères A-G. Brood care and social evolution in termites. Proc R Soc Lond, Ser B: Biol Sci. 2012; 279(1738): 2662-71.

25. Korb J. Termites, hemimetabolous diploid white ants? Front Zool. 2008; 5: 15

26. Shellman-Reeve JS. The spectrum of eusociality in termites. In: Choe JCC, Bernard J, editor. The evolution of social behavior in insects and arachnids. Cambridge: Cambridge University Press; 1997: 52-93.

27. Perry S, Chapman T, Schwarz M, Crespi B. Proclivity and effectiveness in gall defence by soldiers in five species of gall-inducing thrips: benefits of morphological caste dimorphism in two species (Kladothrips intermedius and $\mathrm{K}$. habrus). Behav Ecol Sociobiol. 2004; 56(6): 602-10.

28. Breed MD, Robinson GE, Page RE. Division of labor during honey bee colony defense. Behav Ecol Sociobiol. 1990; 27(6): 395-401.

29. Robinson GE. Modulation of alarm pheromone perception in the honey bee: evidence for division of labor based on hormonally regulated response thresholds. J Comp Physiol, A. 1987; 160(5): 613-9.

30. Giray T, Giovanetti M, West-Eberhard MJ. Juvenile hormone, reproduction, and worker behavior in the neotropical social wasp Polistes canadensis. Proc Natl Acad Sci U S A. 2005; 102(9): 3330-5.

31. Bignell DE, Roisin Y, Lo N. Biology of termites: a modern synthesis. London: Springer; 2011.

32. Crespi BJ, Carmean DA, Chapman TW. Ecology and evolution of galling thrips and their allies. Annu Rev Entomol. 1997; 42(1): 51-71.

33. Wheeler DE. The developmental basis of worker caste polymorphism in ants. Am Nat. 1991; 138(5): 1218-38.

34. Wilson EO. The origin and evolution of polymorphism in ants. Q Rev Biol. 1953; 28(2): 136-56.

35. Baroni Urbani C, Passera L. Origin of ant soldiers. Nature. 1996; 383(6597): 223.

36. Baroni Urbani C. The number of castes in ants, where major is smaller than minor and queens wear the shield of the soldiers. Insect Soc. 1998; 45(3): 315-33.

37. Ward PS. Ant soldiers are not modified queens. Nature. 1997; 385: 494-5.

38. Henderson G. Primer pheromones and possible soldier caste influence on the evolution of sociality in lower termites. In: Vander Meer RK, Breed MD, Espelie KE, Winston ML, ed. Pheromone communication in social insects. Boulder, Colo: Westview Press; 1998: 314-30.

39. Miura T. Morphogenesis and gene expression in the soldier-caste differentiation of termites. Insect Soc. 2001; 48: 216-23.

40. Noirot C, Pasteels J. Ontogenetic development and evolution of the worker caste in termites. Cell Mol Life Sci. 1987; 43(8): 851-60.

41. Ijichi N, Shibao H, Miura T, Matsumoto T, Fukatsu T. Soldier differentiation during embryogenesis of a social aphid, Pseudoregma bambucicola. Entomol Sci. 2004; 7(2): 143-55.

42. Shibao H, Kutsukake M, Fukatsu T. The proximate cue of density-dependent soldier production in a social aphid. J Insect Physiol. 2004; 50(2): 143-7. 
43. Shibao H, Kutsukake M, Fukatsu T. Density-dependent induction and suppression of soldier differentiation in an aphid social system. J Insect Physiol. 2004; 50(11): 995-1000.

44. Mound LA, Crespi BJ. Biosystematics of two new gall-inducing thrips with soldiers (Insecta: Thysanoptera) from Acacia trees in Australia. J Nat Hist. 1995; 29(1): 147-57.

45. Kranz BD. Egg size and reproductive allocation in eusocial thrips. Behav Ecol. 2005; 16(4): 779-87.

46. TÓTh E, Duffy JE. Influence of sociality on allometric growth and morphological differentiation in sponge-dwelling alpheid shrimp. Biol J Linn Soc. 2008; 94(3): 527-40.

47. Duffy E, Morrison C, Macdonald K. Colony defense and behavioral differentiation in the eusocial shrimp Synalpheus regalis. Behav Ecol Sociobiol. 2002; 51(5): 488-95.

48. Leung TLF, Poulin R. Small worms, big appetites: ratios of different functional morphs in relation to interspecific competition in trematode parasites. Int J Parasitol. 2011; 41(10): 1063-8.

49. Newey P, Keller L. Social evolution: war of the worms. Curr Biol. 2010; 20(22): R985-R7.

50. Giron D, Ross KG, Strand MR. Presence of soldier larvae determines the outcome of competition in a polyembryonic wasp. J Evol Biol. 2007; 20(1): 165-72.

51. Gordon SD, Strand MR. The polyembryonic wasp Copidosoma floridanum produces two castes by differentially parceling the germ line to daughter embryos during embryo proliferation. Dev Genes Evol. 2009; 219(9-10): 445-54.

52. Smith MS, Milton I, Strand MR. Phenotypically plastic traits regulate caste formation and soldier function in polyembryonic wasps. J Evol Biol. 2010; 23(12): 2677-84.

53. Giron D, Harvey JA, Johnson JA, Strand MR. Male soldier caste larvae are non-aggressive in the polyembryonic wasp Copidosoma floridanum. Biol Lett. 2007; 3(4): 431-4

54. Grbic M, Ode PJ, Strand MR. Sibling rivalry and brood sex ratios in polyembryonic wasps. Nature. 1992; 360: 254-6.

55. Crespi BJ, Carmean DA, Mound LA, Worobey M, Morris D. Phylogenetics of social behavior in Australian gall-forming thrips: evidence from mitochondrial DNA sequence, adult morphology and behavior, and gall morphology. Mol Phylogen Evol. 1998; 9(1): 163-80.

56. Prestwich GD. Defense mechanisms of termites. Annu Rev Entomol. 1984; 29(1): 201-32.

57. Scheffrahn RH, Křeček J, Su N-Y, Roisin Y, Chase JA, Mangold JR. Extreme mandible alteration and cephalic phragmosis in a drywood termite soldier (Isoptera: Kalotermitidae: Cryptotermes) from Jamaica. Fla Entomol. 1998; 81(2): 238-40.

58. Matsuura K. Colony-level stabilization of soldier head width for head-plug defense in the termite Reticulitermes speratus (Isoptera: Rhinotermitidae). Behav Ecol Sociobiol. 2002; 51(2): 172-9.

59. Wilson EO. The soldier of the ant, Camponotus (Colobopsis) fraxinicola, as a trophic caste. Psyche. 1974; 81(1): 182-8.

60. Weber NA, Schneirla TC. A new Panama Eciton (Hymenoptera, Formicidae). Am Mus Novit. 1949; 1441: 1-8.

61. Huang $\mathrm{M}$, Wheeler D. Colony demographics of rare soldier-polymorphic worker caste systems in Pheidole ants (Hymenoptera, Formicidae). Insect Soc. 2011; 58(4): 539-49.

62. Hasegawa E. Caste specialization in food storage in the dimorphic ant Colobopsis nipponicus (Wheeler). Insect Soc. 1993; 40(3): 261-71.

63. Benton TG, Foster WA. Altruistic housekeeping in a social aphid. Proc R Soc Lond, Ser B: Biol Sci. 1992; 247(1320): 199-202.

64. Pike N, Foster W. Fortress repair in the social aphid species Pemphigus spyrothecae. Anim Behav. 2004; 67(5): 909-14.

65. Kranz B, Schwarz M, Wills T, Chapman T, Morris D, Crespi B. A fully reproductive fighting morph in a soldier clade of gall-inducing thrips (Oncothrips morrisi). Behav Ecol Sociobiol. 2001; 50(2): 151-61.

66. Turnbull C, Caravan H, Chapman T, Nipperess D, Dennison S, Schwarz M, et al. Antifungal activity in thrips soldiers suggests a dual role for this caste. Biol Lett. 2012; 8(4): 526-9.

67. Rosengaus RB, Lefebvre ML, Traniello JF. Inhibition of fungal spore germination by Nasutitermes: evidence for a possible antiseptic role of soldier defensive secretions. J Chem Ecol. 2000; 26: 21-39.

68. Traniello JF. Enemy deterrence in the recruitment strategy of a termite: soldier-organized foraging in Nasutitermes costalis. Proc Natl Acad Sci U S A. 1981; 78: 1976-9.

69. Traniello JF, Leuthold RH. Behavior and ecology of foraging termites. In: Abe T, Bignell DE, Higashi M, ed. Termites: evolution, sociality, symbioses, ecology. Dordrecht: Kluwer Academic; 2000: 141-68.

70. Casarin FE, Costa-Leonardo AM, Arab A. Soldier initiate foraging activities in the subterranean termite, Heterotermes tenuis. J Insect Sci. 2008; 8: 2-5.

71. Olugbemi BO. Exploratory and recruitment phases in soldier-mediated foraging activities in the termite, Coptotermes intermedius Silvestri (Rhinotermitidae: Coptotermitinae). Bull Entomol Res. 2011; 101(4): 423-7.

72. Hanus R, Šobotník J, Cizek L. Egg care by termite soldiers. Insect Soc. 2005; 52(4): 357-9.

73. Bordereau $\mathrm{C}$. The role of pheromones in termite caste differentiation. In: Watson JAL, Okot-Kotber BM, Noirot C, ed. Caste differentiation in social Insects. Oxford: Pergamon Press; 1985: 221-6.
74. Lüscher M. Evidence for an endocrine control of caste determination in higher termites. In: Lüscher M, ed. Phase and caste determination in Insects: endocrine aspects. Oxford Pergamon Press; 1976: 91-103.

75. Thorne BL, Breisch NL, Muscedere ML. Evolution of eusociality and the soldier caste in termites: influence of intraspecific competition and accelerated inheritance. Proc Natl Acad Sci U S A. 2003; 100(22): 12808-13.

76. Haverty MI. The proportion of soldiers in termite colonies: a list and a bibliography (Isoptera). Sociobiology. 1977; 2.

77. Smith CR, Anderson KE, Tillberg CV, Gadau J, Suarez AV. Caste determination in a polymorphic social insect: nutritional, social, and genetic factors. AmNat. 2008; 172(4): 497-507.

78. Wheeler DE. The developmental basis of worker polymorphism in fire ants. J Insect Physiol. 1990; 36(5): 315-22.

79. Passera L, Roncin E, Kaufmann B, Keller L. Increased soldier production in ant colonies exposed to intraspecific competition. Nature. 1996; 379(6566): 630-1.

80. Shibao H. Social structure and the defensive role of soldiers in a eusocial bamboo aphid, Pseudoregma bambucicola (Homoptera: Aphididae): a test of the defence-optimization hypothesis. Res Popul Ecol. 1998; 40(3): 325-33.

81. Akimoto S. Ecological factors promoting the evolution of colony defense in aphids: computer simulations. Insect Soc. 1996; 43(1): 1-15.

82. Harvey JA, Corley LS, Strand MR. Competition induces adaptive shifts in caste ratios of a polyembryonic wasp. Nature. 2000; 406(6792): 183-6.

83. Shingleton AW, Foster WA. Ant tending influences soldier production in a social aphid. Proc R Soc Lond, Ser B: Biol Sci. 2000; 267(1455): 1863-8.

84. Sunose T, Yamana S, Tsuda K, Takasu K. What do the soldiers of Pseudoregma bambucicola (Homoptera, Aphidoidea) defend? Insect. 1991; 59(1): 141-8.

85. Binder BF. Intercolonial aggression in the subterranean termite Heterotermes aureus (Isoptera: Rhinotermitidae). Psyche. 1988; 95(1-2): 123-37.

86. Sun Q, Zhou X. Corpse management in social insects. Int J Biol Sci. 2013; 9(3): 313.

87. Shibao H, Kutsukake M, Fukatsu T. Density triggers soldier production in a social aphid. Proc R Soc Lond, Ser B: Biol Sci. 2004; 271(Suppl 3): S71-S4.

88. Itô Y, Tanaka S, Yukawa J, Tsuji K. Factors affecting the proportion of soldiers in eusocial bamboo aphid, Pseudoregma bambucicola, colonies. Ethol Ecol Evol. 1995; 7(4): 335-45.

89. Shibao H. Reproductive schedule and factors affecting soldier production in the eusocial bamboo aphid Pseudoregma bambucicola (Homoptera, Aphididae). Insect Soc. 1999; 46(4): 378-86.

90. Gibson R. Soldier production in Camponotus novaeboracensis during colony growth. Insect Soc. 1989; 36(1): 28-41.

91. Long C, Thorne B, Breisch N. Termite colony ontogeny: a long-term assessment of reproductive lifespan, caste ratios and colony size in Reticulitermes flavipes (Isoptera: Rhinotermitidae). Bull Entomol Res. 2003; 93(5): 439-45.

92. Fletcher DJ, Ross KG. Regulation of reproduction in eusocial Hymenoptera. Annu Rev Entomol. 1985; 30(1): 319-43.

93. Holman L, Jørgensen CG, Nielsen J, d'Ettorre P. Identification of an ant queen pheromone regulating worker sterility. Proc R Soc Lond, Ser B: Biol Sci. 2010; 277(1701): 3793-800.

94. Hoover SR, Keeling C, Winston M, Slessor K. The effect of queen pheromones on worker honey bee ovary development. Naturwissenschaften. 2003; 90(10): 477-80.

95. Vander Meer RK, Breed MD, Espelie KE, Winston ML. Pheromone communication in social insects. Colorado: Westview Press 1998.

96. Butler C, Callow R, Johnston NC. Extraction and purification of 'queen substance'from queen bees. Nature. 1959; 184(4702): 1871

97. Clarke F, Faulkes C. Dominance and queen succession in captive colonies of the eusocial naked mole-rat, Heterocephalus glaber. Proc R Soc Lond, Ser B: Biol Sci. 1997; 264(1384): 993-1000.

98. Light SF. Experimental studies on ectohormonal control of the development of supplementary reproductives in the termite genus Zootermopsis (formerly Termopsis). Univ Calif Publ Zool. 1944; 43: 413-54.

99. Lüscher M. Social control of polymorphism in termites. In: Kennedy JS, ed. Insect polymorphism. London: Royal entomological society; 1961: 57-65.

100. Matsuura K, Himuro C, Yokoi T, Yamamoto Y, Vargo EL, Keller L. Identification of a pheromone regulating caste differentiation in termites. Proc Natl Acad Sci USA. 2010; 107(29): 12963-8.

101. Maekawa K, Nakamura S, Watanabe D. Termite soldier differentiation in incipient colonies is related to parental proctodeal trophallactic behavior. Zool Sci. 2012; 29(4): 213-7.

102. Bordereau C, Han SH. Stimulatory influence of the queen and king on soldier differentiation in the higher termites Nasutitermes lujae and Cubitermes fungifaber. Insect Soc. 1986; 33(3): 296-305.

103. Springhetti A. Influence of the king and queen on the differentiation of soldiers in Kalotermes flavicollis Fabr.(Isoptera). Monitore Zool Ital. 1970; 4(3): 99-105.

104. Waller D, La Fage J. Environmental influence on soldier differentiation in Coptotermes formosanus Shiraki (Rhinotermitidae). Insect Soc. 1988; 35(2): 144-52.

105. Liu Y, Henderson G, Mao L, Laine RA. Effects of temperature and nutrition on juvenile hormone titers of Coptotermes formosanus (Isoptera: Rhinotermitidae). Ann Entomol Soc Am. 2005; 98(5): 732-7.

106. Park YI, Raina A. Factors regulating caste differentiation in the Formosan subterraneantermite with emphasis on soldier formation. Sociobiology. 2003; 41(1A): 49-60. 
107. Horiuchi S, Yamamura N, Abe T. Soldier production strategy in lower termite: from young instars or old instars? J Theor Biol. 2002; 218(2): 195-205.

108. Wheeler DE. A neglected factor in evolution. Science 1902; 15: 766.

109. McGlynn TP, Owen J. Food supplementation alters caste allocation in a natural population of Pheidole flavens, a dimorphic leaf-litter dwelling ant. Insect Soc. $2002 ; 49(1)$ : 8-14

110. Wheeler DE, Nijhout FH. Soldier determination in Pheidole bicarinata: inhibition by adult soldiers. J Insect Physiol. 1984; 30(2): 127-35.

111. Passera L. Differentiation of the soldiers in the ant Pheidole pallidula Nyl. (Formicidae: Myrmicinae). Insect Soc. 1974; 21(1): 71-86.

112. Rachinsky A, Strambi C, Strambi A, Hartfelder K. Caste and metamorphosis: hemolymph titers of juvenile hormone and ecdysteroids in last instar honeybee larvae. Gen Comp Endocrinol. 1990; 79(1): 31-8.

113. Scharf ME, Ratliff CR, Hoteling JT, Pittendrigh BR, Bennett GW. Caste differentiation responses of two sympatric Reticulitermes termite species to juvenile hormone homologs and synthetic juvenoids in two laboratory assays. Insect Soc. 2003; 50(4): 346-54.

114. Schulz DJ, Sullivan JP, Robinson GE. Juvenile hormone and octopamine in the regulation of division of labor in honey bee colonies. Horm Behav. 2002; 42(2): 222-31.

115. Liu Y, Henderson G, Mao L, Laine RA. Seasonal variation of juvenile hormone titers of the Formosan subterranean termite, Coptotermes formosanus (Rhinotermitidae). Environ Entomol. 2005; 34(3): 557-62.

116. Lenz $\mathrm{M}$. The dependence of hormone effects in termite caste determination on external factors. In: Luscher M, ed. Phase and caste determination in insects. Oxford: Pergamon Press; 1976: 73-89.

117. Scharf ME, Buckspan CE, Grzymala TL, Zhou X. Regulation of polyphenic caste differentiation in the termite Reticulitermes flavipes by interaction of intrinsic and extrinsic factors. J Exp Biol. 2007; 210(24): 4390-8.

118. Scharf ME, Ratliff CR, Wu-Scharf D, Zhou X, Pittendrigh BR, Bennett GW. Effects of juvenile hormone III on Reticulitermes flavipes: changes in hemolymph protein composition and gene expression. Insect Biochem Mol Biol. 2005; 35(3): 207-15.

119. Howard RW, Haverty MI. Termites and juvenile hormone analogues: a review of methodology and observed effects. Sociobiology. 1979; 4(2): 269-78.

120. Mao L, Henderson G, Liu Y, Laine RA. Formosan subterranean termite (Isoptera: Rhinotermitidae) soldiers regulate juvenile hormone levels and caste differentiation in workers. Ann Entomol Soc Am. 2005; 98(3): 340-5.

121. Cornette R, Gotoh H, Koshikawa S, Miura T. Juvenile hormone titers and caste differentiation in the damp-wood termite Hodotermopsis sjostedti (Isoptera, Termopsidae). J Insect Physiol. 2008; 54(6): 922-30.

122. Korb J, Roux EA, Lenz M. Proximate factors influencing soldier development in the basal termite Cryptotermes secundus (Hill). Insect Soc. 2003; 50(4): 299-303.

123. Wheeler DE, Nijhout HF. Soldier determination in ants: new role for juvenile hormone. Science. 1981; 213(4505): 361-3.

124. Rajakumar R, San Mauro D, Dijkstra MB, Huang MH, Wheeler DE, Hiou-Tim $\mathrm{F}$, et al. Ancestral developmental potential facilitates parallel evolution in ants. Science. 2012; 335(6064): 79-82.

125. Lefeuve $P$, Bordereau $C$. Soldier formation regulated by a primer pheromone from the soldier frontal gland in a higher termite, Nasutitermes lujae. Proc Natl Acad Sci U S A. 1984; 81(23): 7665-8.

126. Tarver MR, Schmelz EA, Rocca JR, Scharf ME. Effects of soldier-derived terpenes on soldier caste differentiation in the termite Reticulitermes flavipes. J Chem Ecol. 2009; 35(2): 256-64.

127. Tarver MR, Schmelz EA, Scharf ME. Soldier caste influences on candidate primer pheromone levels and juvenile hormone-dependent caste differentiation in workers of the termite Reticulitermes flavipes. J Insect Physiol. 2011; 57(6): 771-7.

128. Koshikawa S, Cornette R, Matsumoto T, Miura T. The homolog of Ciboulot in the termite (Hodotermopsis sjostedti): a multimeric beta-thymosin involved in soldier-specific morphogenesis. BMC Dev Biol. 2010; 10(1): 63.

129. Zhou X, Oi FM, Scharf ME. Social exploitation of hexamerin: RNAi reveals a major caste-regulatory factor in termites. Proc Natl Acad Sci U S A. 2006; 103(12): 4499-504.

130. Hattori A, Sugime Y, Sasa C, Miyakawa H, Ishikawa Y, Miyazaki S, et al. Soldier morphogenesis in the damp-wood termite is regulated by the insulin signaling pathway. J Exp Zool B Mol Dev Evol. 2013; 320(5): 295-306.

131. Thorne BL. Evolution of eusociality in termites. Annu Rev Ecol Syst. 1997; 28: $27-54$.

132. Korb J. Workers of a drywood termite do not work. Front Zool. 2007; 4: 7 .

133. Walker J, Stamps J. A test of optimal caste ratio theory using the ant Camponotus (Colobopsis) Impressus. Ecology. 1986; 67(4): 1052-62.

134. Noirot C. Pathways of caste development in the lower termites. Oxford: Pergamon Press; 1985.

135. Nutting W. Flight and colony foundation. In: Krishna K, Weesner FM, ed. Biology of termites. New York: Academic Press Inc; 1969: 233-82.

136. Mikus S, Brandl R, Kaib M. Tree-use by Schedorhinotermes lamanianus (Isoptera: Rhinotermitidae). Mitt Dtsch Ges Allg Angew Ent. 1997; 11: 193-7.

137. Husseneder C, Kaib M, Epplen C, Epplen J, Brandl R. Small scale population structure of the termite Schedorhinotermes lamanianus: aggression modulated by genetic and environmental factors. Mitt Dtsch Gesell Allg Angew Ent. 1997; 11: $183-7$.

138. Moran N. Defenders in the North American aphid Pemphigus obesinymphae. Insect Soc. 1993; 40(4): 391-402.
139. Duffy JE, Morrison CL. Multiple origins of eusociality among sponge-dwelling shrimps (synalpheus). Evolution. 2000; 54(2): 503-16.

140. Yang AS, Martin $\mathrm{CH}$, Nijhout HF. Geographic variation of caste structure among ant populations. Curr Biol. 2004; 14(6): 514-9.

141. Mertl A, Traniello JA. Behavioral evolution in the major worker subcaste of twig-nesting Pheidole (Hymenoptera: Formicidae): does morphological specialization influence task plasticity? Behav Ecol Sociobiol. 2009; 63(10): 1411-26.

142. Thompson G, Kitade O, Lo N, Crozier R. Phylogenetic evidence for a single, ancestral origin of a 'true'worker caste in termites. J Evol Biol. 2000; 13(6): 869-81.

143. Wilson EO, Hölldobler B. Eusociality: Origin and consequences. Proc Natl Acad Sci U S A. 2005; 102(38): 13367-71.

144. Hughes WO, Oldroyd BP, Beekman M, Ratnieks FL. Ancestral monogamy shows kin selection is key to the evolution of eusociality. Science. 2008; 320(5880): 1213-6.

145. Herrera EA. Ecological and genetic distribution of eusociality: the case for kin selection. Behav Ecol. 2013; 24(2): 331-3.

146. Crozier RH. Advanced eusociality, kin selection and male haploidy. Aust J Entomol. 2008; 47(1): 2-8.

147. Abbot P, Abe J, Alcock J, Alizon S, Alpedrinha JA, Andersson M, et al. Inclusive fitness theory and eusociality. Nature. 2011; 471(7339): E1-E4.

148. Strassmann JE, Page Jr RE, Robinson GE, Seeley TD. Kin selection and eusociality. Nature. 2011; 471(7339): E5-E6.

149. Howard KJ, Thorne BL. Eusocial evolution in termites and Hymenoptera. In: Bignell DE, Roisin, Yves. Lo Nathan, ed. Biology of termites: a modern synthesis: Springer; 2011: 97-132.

150. Kobayashi K, Hasegawa E, Yamamoto Y, Kawatsu K, Vargo EL, Yoshimura J, et al. Sex ratio biases in termites provide evidence for kin selection. Nat Commun. 2013; 4 .

151. Shibao H. Lack of kin discrimination in the eusocial aphid Pseudoregma bambucicola (Homoptera: Aphididae). J Ethol. 1999; 17(1): 17-24.

152. Abbot P, Withgott JH, Moran NA. Genetic conflict and conditional altruism in social aphid colonies. Proc Natl Acad Sci U S A. 2001; 98(21): 12068-71.

153. Roux EA, Korb J. Evolution of eusociality and the soldier caste in termites: a validation of the intrinsic benefit hypothesis. J Evol Biol. 2004; 17(4): 869-75.

154. Husseneder C, Brandl R, Epplen C, Epplen JT, Kaib M. Within-colony relateness in a termite species: genetic roads to eusociality? Behaviour. 1999; 136: 1045-63.

155. Bourke AF. Social evolution in ants: Princeton University Press. 1995.

156. Boomsma J, Grafen A. Colony-level sex ratio selection in the eusocial Hymenoptera. J Evol Biol. 1991; 4(3): 383-407.

157. Duffy JE, Macdonald KS. Kin structure, ecology and the evolution of social organization in shrimp: a comparative analysis. Proc R Soc Lond, Ser B: Biol Sci. 2010; 277(1681): 575-84

158. Boomsma JJ. Lifetime monogamy and the evolution of eusociality. Phil Trans R Soc Lond B. 2009; 364(1533): 3191-207.

159. Bartz SH. Evolution of eusociality in termites. Proc Natl Acad Sci U S A. 1979; 76(11): 5764-8

160. Lacy RC. The evolution of eusociality in termites: a haplodiploid analogy? Am Nat. 1980; 116(3): 449-51.

161. McLeish M, Chapman T, Crespi B. Inbreeding ancestors: the role of sibmating in the social evolution of gall thrips. J Hered. 2006; 97(1): 31-8.

162. Chapman TW, Crespi BJ, Kranz BD, Schwarz MP. High relatedness and inbreeding at the origin of eusociality in gall-inducing thrips. Proc Natl Acad Sci U S A. 2000; 97(4): 1648-50.

163. Adams ES, Atkinson L, Bulmer MS. Relatedness, recognition errors, and colony fusion in the termite Nasutitermes corniger. Behav Ecol Sociobiol. 2007; 61(8): 1195-201.

164. Johnson PC, Whitfield JA, Foster WA, Amos W. Clonal mixing in the soldier-producing aphid Pemphigus spyrothecae (Hemiptera: Aphididae). Mol Ecol. 2002; 11(8): 1525-31.

165. Carlin NF, Gladstein DS, Berry AJ, Pierce NE. Absence of kin discrimination behavior in a soldier-producing aphid, Ceratovacuna japonica (Hemiptera: Pemphigidae; Cerataphidini). J N Y Entomol Soc. 1994;: 287-98.

166. Gobin B, Ito F. Queens and major workers of Acanthomyrmex ferox redistribute nutrients with trophic eggs. Naturwissenschaften. 2000; 87(7): 323-6.

167. Peeters C, Lin C-C, Quinet Y, Segundo GM, Billen J. Evolution of a soldier caste specialized to lay unfertilized eggs in the ant genus Crematogaster ( subgenus: Orthocrema). Arthropod Struct Dev. 2013; 42: 257-64.

168. Roisin Y. Philopatric reproduction, a prime mover in the evolution of termite sociality? Insect Soc. 1999; 46(4): 297-305.

169. Myles TG. Reproductive soldiers in the Termopsidae (Isoptera). Pan-Pac Entomol. 1986; 62: 293-9.

170. Wheeler WM. Ants: their structure, development and behavior. Columbia University Press. 1910.

171. Kamiya T, O'Dwyer K, Nuy J, Poulin R. What determines the growth of individual castes in social trematodes? Evol Ecol. 2013; 27: 1235-47.

172. Myles TG. Evidence of parental and/or sibling manipulation in three species of Termites in Hawaii (Isoptera). Proc Hawaiian Entomol Soc. 1986; 27: 129-36.

173. Hechinger RF, Wood AC, Kuris AM. Social organization in a flatworm: trematode parasites form soldier and reproductive castes. Proc R Soc Lond, Ser B: Biol Sci. 2011; 278(1706): 656-65. 
174. Beggs KT, Glendining KA, Marechal NM, Vergoz V, Nakamura I, Slessor KN, et al. Queen pheromone modulates brain dopamine function in worker honey bees. Proc Natl Acad Sci USA. 2007; 104(7): 2460-4.

175. Kutsukake M, Shibao H, Nikoh N, Morioka M, Tamura T, Hoshino T, et al. Venomous protease of aphid soldier for colony defense. Proc Natl Acad Sci U S A. 2004; 101(31): 11338-43.

176. Sobotnik J, Jirosova A, Hanus R. Chemical warfare in termites. J Insect Physiol. 2010; 56(9): 1012-21.

177. Fuller CA. Fungistatic activity of freshly killed termite, Nasutitermes acajutlae, soldiers in the Caribbean. J Insect Sci. 2007; 7.

178. Huang MH. Multi-phase defense by the big-headed ant, Pheidole obtusospinosa, against raiding army ants. J Insect Sci. 2010; 10: 1.

179. Wilson E. The relation between caste ratios and division of labor in the ant genus Pheidole (Hymenoptera: Formicidae). Behav Ecol Sociobiol. 1984; 16(1): 89-98.

180. Wilson EO. Division of labor in fire ants based on physical castes (Hymenoptera: Formicidae: Solenopsis). J Kans Entomol Soc. 1978; 51(4): 615-36. 